\title{
Ortega y Hegel. \\ La interpretación de la historia y sus trampas"
}

\author{
Ortega and Hegel. \\ The interpretation of history and its pitfalls
}

\begin{abstract}
Resumen: Se revisan los tres ensayos y las abundantes notas de trabajo que Ortega dedicó al pensamiento de Hegel, especialmente a su filosofía de la historia. Se trata de una dedicación relativamente escueta en el conjunto de la obra de Ortega, pero nada insignificante ya que ilumina diversos aspectos de su reflexión sobre la historia. Entre otros, su noción de "historiología" y sus críticas del historicismo, el eurocentrismo y, por supuesto, del idealismo. En este sentido, todo su pensamiento cabría ser interpretado como una especie de reducción del idealismo hegeliano, encaminada a liberar la experiencia vital de la tiranía conceptual y del determinismo dialéctico del Espíritu.
\end{abstract}

Palabras clave: Ortega, Hegel, filosofía de la historia, vida, Espíritu.
ANTOLÍN SÁNCHEZ CUERVO**

\begin{abstract}
There are reviewed the three essays and the abundant notes of work that Ortega y Gasset dedicated to Hegel's thought, specially to his philosophy of the history. It is about a rather concise question in the set of Ortega's work, but not insignificant at all since it illuminates several aspects of his reflection on the history. Between others, his notion of 'Historiology' and his critiques of Historicism, Eurocentrism and, of course, Idealism. In this respect, all his could be interpreted as a species of reduction of the Hegelian idealism, directed to liberating the vital experience of the conceptual tyranny and of the dialectical determinism of the Spirit.
\end{abstract}

Keywords: Ortega, Hegel, Philosophy of History, life, Spirit.

1. La presencia de Hegel en el pensamiento de Ortega es relativamente escueta, pero mayor de la que pudiera parecer a primera vista. Si bien el nombre de Hegel - clásico ineludible del pensamiento moderno y autor de referencia, por tanto, para cualquier pensador de la posteridad - aparece en los índices analíticos de las obras completas de Ortega de manera constante, su referencia en el universo filosófico de este último es menos significativa que la de otros "clásicos" como - por supuesto - Leibniz o el propio Kant. Sin dejar de constituir

Fecha de recepción: 19/05/2014. Fecha de aceptación: 02/12/2014.

* La presente contribución ha sido realizada en el marco del proyecto de investigación El pensamiento del exilio español de 1939 y la construcción de una racionalidad política (FFI2012-30822), financiado por el Ministerio de Economía y Competitividad.

** Investigador en el Instituto de Filosofía-CCHS (Consejo Superior de Investigaciones Científicas), Madrid. Correo-e: antolin.scuervo@cchs.csic.es 
una referencia obligada en cualquier cultura filosófica amplia y madura, como la de Ortega en este caso, Hegel nunca llegó a influir de una manera substancial en su pensamiento, por razones obvias. Si nos fijamos en la tópica división establecida por Dilthey en su teoría de la concepción del mundo, Hegel aparece como un autor prototípico del "idealismo objetivo"; es decir, de aquella "Weltanschauung" que considera el universo una totalidad en la que cada parte se halla determinada por un nexo ideal que todo lo recorre, en la que todas las cosas se hallan interrelacionadas entre sí y en la que sujeto y objeto, razón y realidad, terminan por identificarse en virtud de una conexión necesaria y en última instancia divina. Bien diferente es el perfil del "idealismo de la libertad" o "de la personalidad", con algunos de cuyos aspectos Ortega quizá podría congeniar y que Dilthey entiende como "necesidad de libertad frente al determinismo"2 - ya sea éste de carácter naturalista o metafísico - , como primacía de la acción, originada en la vitalidad espontánea, y como afirmación de los hechos de la conciencia en el orden del conocimiento.

Esta lejanía cosmovisional puede apreciarse en la escasez de escritos que Ortega dedicó de manera monográfica a Hegel y que se reducen a tres ensayos más o menos breves: en primer lugar, "La Filosofía de la historia de Hegel y la historiología", publicado en la Revista de Occidente en febrero de 1928 y escrito con la intención inicial de prologar la traducción de José Gaos de las Lecciones sobre la filosofía de la historia universal del pensador alemán ${ }^{3}$, con la que Ortega inauguraba una "Biblioteca de historiología". En segundo lugar, "Hegel y América", fechado también en 1928 y publicado en El espectador VII (1930) ${ }^{4}$. Finalmente, "En el centenario de Hegel", publicado por primera en La Nación de Buenos Aires a comienzos de 1932, formando parte después de Ideas y creencias $(1940)^{5}$, y que se trataba en realidad de una nueva versión de una conferencia pronunciada en el Instituto Internacional de Señoritas el 14 de diciembre de 1931 bajo el título "Hegel y la filosofía de la historia", reproducida en El Sol el día siguiente ${ }^{6}$. Se trata además de artículos más bien expositivos, en los que incluso se puede apreciar un cierto tono de homenaje, en detrimento del tono polémico, y en los que puede echarse de menos, por tanto, el desahogo crítico que cabría esperar de una lectura del idealismo hegeliano en clave raciovitalista.

Ahora bien, a esos artículos habría que añadir un abundante material de trabajo, editado por Domingo Hernández en 20077 , en el que ese tono crítico se hace más palpable. Lo conforman notas de lectura y comentarios del propio Ortega que después serán parcialmente revisados y "pulidos" para su publicación, y que, de acuerdo con dicha edición,

1 Dilthey, Wilhelm: Teoría de la concepción del mundo. Traducción, prólogo y notas de Eugenio Ímaz. México, FCE, 1978 ( $1^{\text {a }}$ ed. en 1945), p. 141.

2 Ibid., p. 138.

3 Cf. Ortega y Gasset, José: Obras completas. Madrid, Fundación Ortega y Gasset-Taurus, 2006, tomo V, pp. 229-247.

4 Cf. Ortega y Gasset, José: Obras completas. Madrid, Fundación Ortega y Gasset-Taurus, 2004, tomo II, pp. 667-679.

5 Cf. Ibid., tomo V, pp. 687-704.

6 Cf. Ibid., tomo VIII, pp. 521-533.

7 Ortega y Gasset, José: Hegel. Notas de trabajo. Ed. de Domingo Hernández Sánchez. Madrid, Fundación Ortega y Gasset-Abada editores, 2007. Incluye además, a manera de apéndice, el texto original de la mencionada conferencia sobre Hegel en el Instituto Internacional de Señoritas (pp. 183-203), reproducido después (con muy ligeras variaciones) en el tomo VIII de las Obras completas. 
pueden encuadrarse en tres momentos de la trayectoria intelectual de Ortega: el primero, el más amplio y también el más difuso en cuanto a temas, abarcaría sus años de juventud; el segundo, acaso el más significativo, el intervalo que comprende los últimos años veinte y los comienzos de la década siguiente, coincidiendo con la elaboración de los artículos arriba mencionados y con su segunda estancia en Buenos Aires (1928), durante la que impartió algunas lecciones de historiología y dialéctica (1928); el tercero, finalmente, la década de los cuarenta, en la que Ortega dedicará abundantes notas al problema de la dialéctica.

Pero, como ya hemos adelantado, esta pequeña constelación de escritos sobre Hegel, sin dejar de ser escueta y mucho menos relevante que la de otros clásicos del pensamiento moderno en el universo intelectual de Ortega, resulta más significativa de lo que pudiera parecer en primera instancia, por dos razones:

Primero, porque conecta con áreas y cuestiones diversas del pensamiento orteguiano, especialmente aquellas relacionadas con el problema de la historia. Hegel asoma así, de diversas maneras, en la reflexión de Ortega sobre la historia.

Segundo, y englobando lo anterior, porque el pensamiento de Ortega en su conjunto cabría ser interpretado como una suerte de reducción del idealismo hegeliano, encaminada a liberar la experiencia vital de la tiranía conceptual y del determinismo dialéctico del Espíritu, a devolverle su autenticidad y su radical inseguridad, finalmente escamoteada por la arquitectura colosal de Hegel. Obviamente, no se trataría de una reducción premeditada o señalada por Ortega como un objetivo, un propósito o un hilo conductor de su pensamiento, pero sí de algo implícito a lo largo de su larga meditación sobre las relaciones entre la razón y la vida. Una reducción, por tanto, de la especulación ideal a la experiencia vital, del Espíritu como autoconciencia de un saber absoluto a la vida como imposibilidad de saberse a sí misma, lo cual bien podría desgranarse en numerosas reducciones particulares: del "nosotros" entendido como un macrosujeto o un sujeto autorreflexivo que subsume lo colectivo bajo una identidad común, al "nosotros" de un sujeto trans-individual o sociológico, a la modesta subjetividad del individuo afanoso por convivir con los otros partiendo de su radical soledad - véase El hombre y la gente-. Del estado como eticidad o como una totalidad que alcanza la libertad en la autodeterminación negativa del individuo, al estado como un constructo liberal que preserva, por tanto, la entidad irreductible e inalienable de ese mismo individuo - véase La rebelión de las masas - . De la trabazón dialéctica a la tensión, siempre inconclusa y celada por la incertidumbre, entre inmanencia y trascendencia. De la Historia Universal o la filosofía de la historia en su expresión más canónica, en clave de progreso lineal al modo de la Ilustración y el idealismo, a una fenomenología de la realidad histórica o una "historiología", tal y como leemos en el encabezamiento de uno de los ensayos que Ortega dedica a Hegel.

En definitiva, una reducción múltiple al término de la cual la vida deja de ser destino para recuperar su genuino carácter de aventura. Vida sin Espíritu, lo cual, lejos de agotarse en un conjunto más o menos inconexo, irracional, contradictorio y opaco de hechos, vivencias y acontecimientos, encuentra en sí misma, en su propio trajín, en su propia actividad inmanente aunque siempre proyectiva y dotada de recursos conceptuales y apriorísticos, su razón de ser. Vida cuya actividad natural no es la navegación sino el naufragio, como tampoco es la explicación resolutiva, casi tautológica, sino la interpretación problemática de sí misma, en busca de un sentido y una justificación siempre esquivos. "En vez de espíritu" — escri- 
birá Ortega en una de sus notas- "pongamos 'vida' en mi sentido. La vida es un buscarse a si misma - una lucha por su propia autenticidad. Esto es buscar "el sentido de la vida". 8

Ortega no es, sin embargo, un anti-hegeliano sin más, ya sea en clave existencialista - a pesar de sus concomitancias con la fenomenología existencial-, o - menos aúnmaterialista. Por eso su reducción del idealismo hegeliano no adopta en ningún momento - ni lo pretende - el cariz radicalizado de una hermenéutica de la sospecha o de una teoría crítica - aun a pesar de haber leído a un crítico de Hegel tan penetrante como inadvertido en España, como Franz Rosenzweig ${ }^{9}$ - , reconduciéndolo más bien hacia el terreno de sus propias preocupaciones e incluso adaptándolo a la horma de ellas. La crítica convivirá así, en algunos momentos, con la complicidad.

2. Para Ortega, vida sin Espíritu no es lo mismo que vida sin ideas. "La Filosofía de la historia de Hegel y la historiología" gira, en buena medida, en torno a esta distinción. Que entre la historia racional y la razón histórica haya una distancia insalvable es algo que este ensayo parece dar por descontado y que se hará explícito en los otros dos ensayos de Ortega sobre Hegel, así como en sus notas de trabajo. Por ahora, Ortega incluso parece buscar cierta complicidad con Hegel — precedente de la historiología, a pesar de sus excesos - , para desmarcarse de otras maneras de reducir la concepción idealista de la historia, algo toscas o excesivamente simples a su juicio, y, al hilo de esto mismo, esbozar una concepción propia de la historia y algunas claves para su interpretación. Se desmarca así, en concreto, de la historiografía dominante en su época, la reconstrucción supuestamente científica del pasado amparada bajo la "escuela histórica" de Ranke. Ortega, bien es cierto, comparte la rebelión historicista contra el despotismo hegeliano:

(...) ante todo es preciso reconocer que la escuela histórica comienza por tener razón frente a la escuela filosófica, frente a Hegel. Si la filosofía es, en uno u otro riguroso sentido, lógica, y opera mediante un movimiento de puros conceptos lógicos y pretende deducir lógicamente los hechos a-lógicos, no hay duda de que la historia debe rebelarse contra su intolerable imperialismo. (...) Por lo tanto, nos unimos con los historiadores en su jaquerie contra la llamada filosofía del espíritu, y, aliados con ellos, tomamos la bastilla de este libro hegeliano ${ }^{10}$.

Ahora bien, a partir de esta declaración de intenciones los caminos se bifurcan: que la vida del pasado, tal y como Ortega la entiende, sea irreductible a concepto o a la lógica deshumanizada del Espíritu no significa que se reduzca a hechos muertos y datos empíricos. Estos últimos son sólo el síntoma de una vitalidad que, aun ceñida al ámbito de la expe-

8 Hegel. Notas de trabajo, o.c., p. 48. En una nota a pie de esa misma página, el editor trae muy oportunamente a colación una larga cita de Ortega, extraída de su libro Notas de trabajo. Epílogo (ed. de José Luis Molinuevo. Madrid, Alianza-Fundación Ortega y Gasset, 1994, pp. 348-349), que concluye de la siguiente manera: "La vida es el lugar de los problemas y no el de las soluciones como el Geist de Hegel".

9 Ortega alude a su libro Hegel und der Staat (Munich-Berlin, Oldenbourg, 1920) en una de sus notas de trabajo (p. 131). Un ejemplar de dicho libro formaba parte de la biblioteca personal de Ortega, de la que Domingo Hernández ofrece una pequeña selección en la Introducción a su edición de estas notas de trabajo (pp. 22s).

10 "La Filosofía de la historia de Hegel y la historiología", Obras completas, tomo V, p. 233. 
riencia, exige la elucidación de categorías, estructuras y elementos analíticos -es decir, una historiología - para ser interpretada. Por eso - dirá Ortega, a veces con expresiones muy contundentes e irónicas - la presunción de ciencia que los historiadores profesionales quieren ostentar al hilo del historicismo rankeano es en realidad ingenua y arrogante, pues reduce la historia a crítica filológica, despreciando cualquier desviación heterodoxa del culto al dato y al documento. El historiador echa en cara al filósofo, "casi siempre con pedantería, su falta de documentos. Desde hace un siglo, gracias a la documentación, se siente como un chico con zapatos nuevos" ${ }^{\prime 1}$. Para Ortega, este historicismo obedecería a una mera $-\mathrm{y}$ deficiente - imitación del paradigmas científico característico de la física moderna, que confunde el análisis con la observación y olvida que Galileo necesitó plantear hipótesis a priori para interpretar los datos de la naturaleza. Obvia, en definitiva, que el análisis es una disciplina "ultraempírica" y que la ciencia empieza más allá del dato. Confunde, en este sentido, la ciencia histórica con la hermenéutica filológica, es decir, con un estrato de su metodología, "el llamado estudio de las fuentes, que blanden con ingenua agresividad los historiadores de profesión"12. De ahí - dirá Ortega en una de sus notas de trabajo- el contraste, en la historiografía actual, entre "la precisión en el manejo de los documentos y la imprecisión y miseria en el uso de las ideas constructivas." "13 Contra esta concepción meramente descriptiva "se levanta la historiología" 14 , que es "historia en construcción"15 desde una perspectiva "orgánica y estructural"16 y hasta una "ontología"17, capaz de elucidar elementos invariables o dimensiones primarias sin las que el conocimiento del pasado carecería de objetividad. El propio Ortega plantea los elementos siguientes:

Un núcleo a priori, la analítica del género de realidad que se intente investigar - la materia en física, lo histórico en historia.

Un sistema de hipótesis que enlaza ese núcleo a priori con los hechos observables Una zona de inducciones dirigidas por esas hipótesis

Una vasta periferia rigurosamente empírica - descripción de los puros hechos o datos $^{18}$.

A este respecto, Ortega reconoce el provecho de ciertos elementos categóricos hegelianos tales como el espíritu objetivo, el estado, la religión y los individuos histórico-universales ${ }^{19}$ por la legibilidad que infunden en el conocimiento del pasado; pero no por ello deja de marcar diferencias entre la historiología y la filosofía de la historia - bajo su culminante acepción hegeliana, al menos-. Lo primero no es asimilable a lo segundo, tal y como

11 En una de sus notas de trabajo sobre Hegel afirma en este sentido que del historiador que asegura necesitar sólo documentos se puede decir que "es como el arriero que al contar los burros no hallaba uno, aquel en que iba montado" (pp. 62s.)

12 "La Filosofía de la historia de Hegel y la historiología", o.c., p. 236.

13 Hegel. Notas de trabajo, o.c., p. 79.

14 "La Filosofía de la historia de Hegel y la historiología", o.c., p. 236.

15 Hegel. Notas de trabajo, o.c., p. 102.

16 Ibid., p. 64.

17 "La Filosofía de la historia de Hegel y la historiología", o.c., p. 243.

18 Ibid., p. 236.

19 Cf. Hegel. Notas de trabajo, o.c., p. 68. 
apunta a menudo en sus notas de trabajo. A Hegel - afirma en este sentido - "no le sería nada simpático este propósito de historiología", pues a su juicio "historia no es ciencia sino Darstellung, representación" 20 y hasta "pantomima de la lógica" 21 . Obviamente, para Ortega la reconstrucción del pasado no puede discurrir conforme a ninguna lógica preestablecida, ya que ello anularía su misma sustancia, a saber, la expresión vital inalienable e intransferible de cada momento y cada época, a partir de sus actores contingentes y sus experiencias concretas. Por eso la racionalidad historiológica no puede ser "lógica" sino "ilógica" — es decir, "vital"22 - , en el sentido de que está llamada a afrontar la irracionalidad que a menudo impregna la realidad histórica, sin recurrir a la argucia tautológica del gran relato ni al artificio meta-histórico de la negación dialéctica. En base a esto último, Hegel expropia a la historia su misma historicidad, reduciéndola a "la proyección en el tiempo del proceso lógico, de la evolución lógica" 23 . La historiología discurre en un sentido bien diferente, si es que no inverso. No es "lógica de la historia, sino ratio rerum gestarum, el logos de lo histórico, de la realidad, no del pensamiento que se aplica a lo histórico" 24 , entendiendo esto último como "el lugar o área de la aventura" y hasta como la "naturaleza" o el lugar natural de "lo espiritual" 25 .

Esto no significa, obviamente, que Ortega abogue por un historicismo positivo, lo cual le conduciría al otro extremo del arco, es decir, a aquellos mismos planteamientos rankeanos cuya insuficiencia hacía muy "edificante" el diálogo con Hegel; pero sí por un uso hermenéutico y no inhibidor de ese "núcleo a priori" y esa "analítica" a que se refería, capaz de liberar a la realidad histórica de toda contradicción excluyente entre naturaleza y espíritu, o, dicho de otra manera, de liberarla de la lógica de la representación. Frente a esta última, Ortega plantea una lógica de la interpretación, que restituya la significación histórica que por sí mismas poseen todas aquellas experiencias vitales y dimensiones culturales anegadas bajo las diversas mediaciones dialécticas del Espíritu. "Variación, "rejuvenecimiento" y "razón", entre otras categorías dialécticas apuntadas por Hegel en la Introducción de sus lecciones, forman parte de una especie de representación tautológica de la que Ortega quiere desprenderse para liberar la complexión vital, heterogénea e inmanente del hecho histórico. Por eso lo que le interesa no es, por ejemplo, "qué representa el pueblo griego en el universo histórico", sino "qué y cómo fue y se produjo en su textura interior"; no que el chino crea al Emperador "un hijo del Cielo sino cómo y por qué puede creer semejante cosa" 26 . Lo que le interesa, en definitiva, es “en qué medida el 'espíritu', o sea, el sentido, es interpretación y justificación de la vida" 27 . Al paradigma de la representación y sus objetivaciones especulativas, opone así Ortega el de la interpretación y sus mediaciones subjetivas, las cuales persiguen una elaboración del pasado capaz de integrar todo aquel acontecer supuestamente irreflexivo y opaco que Hegel confinaba al mundo de la Naturaleza.

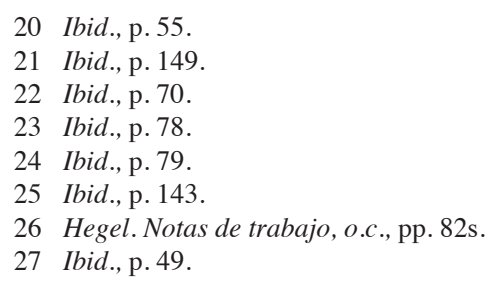


La respuesta de Ortega a la reducción hegeliana de la historia conecta así con las dimensiones narrativas de su pensamiento y con las prolongaciones hermenéuticas de su razón histórica y fenomenológica. En sintonía con un anti-hegeliano ejemplar como Unamuno, pero siguiendo derroteros muy diferentes, apelará a la intrahistoria. A la gran falacia de la historia universal contrapondrá el "proceso intrahistórico" 28 o la "causalidad intrahistórica". 29 Obviamente, dar cuenta de la historia por dentro no significa para Ortega descubrir bajo sus manifestaciones grandilocuentes y superficiales una supuesta tradición eterna y sumergida, silenciosa y relegada, anónima y auténtica, activa en su quietud, y sustancia verdadera de las mismas, tal y como había planteado el Unamuno de En torno al casticismo (1895) - a contrapelo, además, del tradicionalismo, mucho más que del idealismo-. Significa más bien descubrir, interpretar y narrar las tramas de pequeñas historias que, en torno a ciertas constelaciones $-\mathrm{y}$, por supuesto, generaciones- de individuos, se van entrelazando y complicando hasta gestar un determinado suceso epocal. Tampoco significa reconstruir el pasado "desde abajo" o a partir de sus voces excluidas o supuestamente insignificantes, tal y como plantearán algunas décadas después la microhistoria o la historia social británica, por ejemplo. Ortega es más hermeneuta que crítico y pone el acento en la capacidad transformadora de las minorías selectas, mucho más que en la de los sujetos anónimos y desplazados.

En cualquier caso, el papel histórico atribuido a los individuos es precisamente uno de los elementos que mayormente separa a Ortega de Hegel, tal y como anota aquel de manera explícita. "Mi contraposición a Hegel: para él el individuo es la exterioridad del proceso real (lo insignificante) - para mí, al revés" ${ }^{30}$. Para Ortega, el individuo es el gran relegado de la llamada historia universal, con la sola e insuficiente excepción del héroe o individuo histórico-universal, el cual no deja de tener "algo de muñequería, de fantoche" 31 por los hilos de los que pende y que dirigen su movimiento a la manera de un títere del Espíritu. Desde el revés orteguiano, la única instancia que trasciende la acción histórica del individuo es su propia convivencia dramática con otros individuos, dando lugar a sujetos trans-individuales ${ }^{32}$, pero en ningún caso supra-individuales. O como dirá explayadamente en El hombre y la gente, a "relaciones interindividuales", las cuales no son, por cierto, asimilables sin más a las relaciones sociales, pues éstas no dejan de estar lastradas por una condición impersonal, convencional y anónima, propia del "hombre deshumanizado" 33 o "inhumano" 34 , que incluso se torna coercitiva y opresiva cuando se institucionaliza en el poder del estado legitimado por el derecho. Lo social, bajo sus expresiones convencionales, se hace valer entonces no sólo en el amparo entre humanos, sino también en el poder anónimo, en la inanidad coactiva de "la gente", de sus usos automatizados y sus códigos lingüísticos impersonales. En El hombre y la gente, en donde Ortega logra proyectar en un sentido ácrata su siempre impreciso liberalismo, hasta el punto de sugerir, incluso, la tesis

28 Ibid., p. 82.

29 Ibid., p. 84.

30 Ibid., p. 161.

31 Ibid., p. 96.

32 "La estructura de lo subjetivo individual es la psicología, pero la de lo subjetivo transindividual la da precisamente la historiología", Ibid., p. 59.

33 Obras completas, o.c., tomo X, 2010, p. 257.

34 Ibid., p. 264. 
de la violencia como fuente del derecho ${ }^{35}$ que tan suya harán mucho después Agamben o Derridá, entre otros, la sociedad es "nadie". Y algo de este poderío anónimo y tiránico advierte Ortega, a propósito de su propuesta historiológica, en las figuras hegelianas del Espíritu, especialmente cuando alcanzan su plenitud objetiva bajo la forma del estado. Para Ortega, el Espíritu también es un todo que por dentro es nadie, o un "alma colectiva" que "aparece como algo infinitamente superior, infinitamente más humano que el hombre" y, por lo tanto, como "lo humano sin el hombre" o, paradójicamente, "lo humano sin espíritu, lo humano sin alma, lo humano deshumanizado" 36 . Por eso para él la historia por dentro es la narración de las relaciones interindividuales que en una determinada época abrieron un espacio vital entre la soledad radical y la convención social.

3. En "Hegel y América", Ortega expondrá, con un tono moderadamente crítico, la dimensión enajenante de la historia universal, "dimensión de ingenuidad y de crueldad imperial"37 que reduce lo histórico a una "emanación de la razón"38; a una proyección ideal en el tiempo de categorías preestablecidas que, al desplegarse además en términos de progreso y autorreflexión, condiciona y limita la plenitud de cada época en función de su télos; y que se clausura a sí misma una vez que ese télos se consuma en un presente definitivo, identificado con la cultura cristiano-germánica de la que el propio Hegel es fiel depositario e intérprete. Ortega aquilatará esta aproximación al absolutismo lógico que preside la filosofía hegeliana de la historia señalando un doble reduccionismo, en el origen y en el fin.

En el origen porque, de acuerdo con Hegel, la historia universal sólo puede comenzar en aquellos pueblos que han sido capaces de construir un estado: si la historia es la epifanía o la representación del Espíritu, cuya substancia es la autorreflexión o el saber de sí, y por tanto la libertad o la gestación de una identidad "insumisa a mandatos ajenos, dueña y señora de sí misma”, su plasmación habrá de ser necesariamente política. El estado, en tanto que figura de autodeterminación y autolegislación máximas es entonces la realización más perfecta del Espíritu. Con el estado comienza así, para Hegel, "una realidad nueva, sobrenatural; es el anuncio de que nace un orbe cuya sustancia es Libertad." 39 , revelándose irracional y bárbara, natural y prehistórica, toda vida anterior. De ahí que el pasado, para Hegel, sea exclusivo de "aquellos pueblos que formaron claramente un Estado. La vida pre-estatal es irracional, y Hegel, en su racionalización de la historia, no llega a la generosidad de salvarla y justificarla toda." La historia universal de Hegel no es, por tanto, universal, pues sólo puede originarse donde hay un estado. Hegel construye así una historia excluyente al amparo de su concepto de "eticidad" o de una universalidad particularista, identificada con la esfera concreta del estado, que es además la forma en que Europa ha codificado la política.

35 "La coacción máxima es la física y el contorno social la practica cuando se contraviene a un tipo de usos muy característico que se llama 'Derecho'”, afirma en este sentido en la p. 293.

36 Ibid., p. 257. Otra alusión crítica a Hegel en este libro puede encontrarse en la p. 227, a propósito del "movimiento dialéctico" donde cada nuevo paso consiste sólo en la mecánica negación del anterior, y de la "inspiración dialéctica" que Ortega define como "la forma más estúpida de la vida humana, aquella en que precisamente andamos más cerca de comportarnos con un automatismo casi físico".

37 Obras completas, o.c., tomo II, p. 670.

38 Ibid., p. 669.

39 Ibid., p. 672. 
Pero también en el fin, ya que la historia universal, en la medida en que sólo puede ser reconstruida desde la lucidez del presente absoluto que la culmina, cierra toda proyección transformadora hacia el futuro. "El presente, para Hegel, no es un tiempo cualquiera; es éste y sólo éste. Y por eso nuestro presente no cambiará en nada esencial, perdurará idéntico (...). Así acaece que esta filosofía de la historia no tiene futuro, no tiene escape" 40 . La historia termina en el presente, el fin excluye el futuro.

Y qué mejor ejemplo para ilustrar este doble reduccionismo que la reflexión de Hegel sobre América, un continente que, habiendo carecido de un estado antes de ser conquistada por los europeos y habiéndolo construido después de una manera precaria y periférica, bajo el soplo tardío de la cultura europea, ha permanecido en realidad ajena al Espíritu y, por lo tanto, también a la historia. Por eso su tiempo es el de la Prehistoria, en la que todo es Naturaleza o ineptitud para libertad. América, para Hegel, no tiene pasado porque pertenece a la Prehistoria y, consecuentemente, tampoco tiene presente, pues éste no es más que la conciencia plena y total de la totalidad de aquél. En su barbarie congénita, es pretérito absoluto y presente imposible, y si tiene algún futuro, ello es irrelevante porque la historia termina en el presente y al filósofo no le compete hacer profecías, sino reconstruir los caminos que han llegado a la cima en la que él se encuentra. Su esencia es por tanto la novedad, entendida como inmadurez. "Como para Hegel sólo es verdaderamente el Espíritu, la realidad de la Naturaleza consiste en algo que va a ser Espíritu, pero que aún no lo es" ${ }_{41}$, y ese "todavía no" permanente y casi fosilizado es precisamente el rasgo definitorio del Nuevo Mundo en la historia universal. Salvando una paradoja aparente, la Prehistoria es novedad, en el sentido de que todavía no es historia y de que podría estar llamada a serlo, si bien ese hipotético porvenir no forma parte de la razón, ya que ésta se extiende únicamente a lo que ha sido y lo que es.

Pero inmadurez también significa, para Hegel, debilidad. La propia conquista del continente habría mostrado la inferioridad de su cultura y su condición natural, la cual "había de perecer tan pronto como el Espíritu se acercara a ella. América se ha revelado siempre y sigue revelándose impotente, en lo físico como en lo espiritual. Los indígenas, desde el desembarco de los europeos, han ido pereciendo al soplo de la actividad europea"42. En lo físico, por su reciente conformación geológica. En este punto, Hegel -podríamos añadir a la exposición orteguiana de su visión de América-, no hace sino reproducir cierta caracterización pseudo-científica de la naturaleza americana ya acuñada a lo largo de la modernidad, para fundamentar seguidamente, en base a ella, la supuesta inferioridad antropológica del indígena: éste es inferior por su constitución biológica, su tendencia congénita al servilismo, su carencia de destreza técnica y su minoría de edad, lo que le incapacita para la lucha por la libertad o para afrontar toda dialéctica entre amos y siervos. Hegel lleva a su plenitud este discurso abiertamente racista y legitimador de colonialismos de toda índole, que ya había empezado a circular en el siglo XVI de la mano de Ginés de Sepúlveda, en el contexto de los debates sobre la conquista, adaptándose después a la modernidad científica inaugurada

40 Ibid., p. 670.

41 Ibid., p. 673.

42 Hegel, G.W.F.: Lecciones sobre filosofía de la historia universal. Citado por Ortega y Gasset en Obras completas, o.c. tomo II, p. 673. 
por Bacon y actualizándose a lo largo de todo el Enciclopedismo y la Ilustración, Kant inclusive, obviamente con numerosos y diversos contrapuntos ${ }^{43}$.

Hegel recogerá e integrará esta discreta tradición de pensamiento racista en el andamiaje conceptual de su filosofía de la historia universal, en el que tampoco tiene buen encaje, por cierto, la América del Norte. Pese a su mayor benevolencia con los estados surgidos en esta región - apunta Ortega - , influida sin duda por la afinidad de Hegel con el patriotismo protestante y por su desprecio hacia las naciones católicas del sur, aquellos tampoco cumplían a su juicio las condiciones objetivas necesarias para ingresar en la historia universal. El carácter federal y republicano de dichos estados, su protección de la propiedad y de la libertad de individuo y el principio de la industria, sin otros principios de unidad superior que los organice internamente, orienta a los individuos "hacia la ganancia y el provecho" y hacia "la preponderancia del interés particular, que si se aplica a lo universal es sólo para mayor provecho del propio goce". Es decir, les orienta hacia "una legalidad sin justicia" 44 o un estado sin una vida verdaderamente orgánica, algo a lo que además contribuyen otros factores como la ausencia de contradicciones agudas entre clases sociales, mitigadas por las migraciones internas, y la dificultad de concentrar la vida espiritual debido a la escasa densidad de población y las grandes extensiones de los territorios.

En "Hegel y América", Ortega señalaba así uno de los lugares más discretos y al mismo tiempo más elocuentes de la "ingenua crueldad" hegeliana. Sin embargo, al igual que "La filosofía de la historia de Hegel y la historiología", su exposición es más bien descriptiva y cuando se torna crítica lo hace de manera tibia y moderada. Incluso prevalece el tono laudatorio, aun cuando el implícito de su ensayo es esa ingenua crueldad o cuando objeta al pensamiento hegeliano una "ceguera para el futuro" nada inocente, motivada por su "afán imperialista" de sistema frente a todo "apetito frenético de verdad", o por su cerrazón dogmática ante la amenaza de "nuevas posibilidades luminosas" 45 . Cabría algún comentario crítico más incisivo. Ingenua o no, la crueldad hegeliana se hace muy patente en su visión de América. Pudiera parecer que Hegel se limita a levantar acta del pasado y de cómo éste ha condicionado el presente. En el caso de América, es indiscutible que las culturas aborígenes fueron dominadas y reducidas, que la posterior creación de los estados libres, salvo en América del Norte, ha estado muy condicionada por múltiples debilidades, o que su pasado y su presente se ha acotado y definido siempre en función de los intereses de Europa. El problema surge cuando se pretende justificar esa dominación con argumentos pseudo-científicos o pseudos-antropológicos, cuando se quiere reducir la historia universal - en caso de que exista - a la historia de sus figuras dominantes o la universalidad a un asunto exclusivo de Europa - de una cierta Europa, además, de la que no forman parte los pueblos del sur-;

43 Cf. el clásico libro de Antonello Gerbi La disputa del Nuevo Mundo. Storia di una polemica. 1750-1900 Milano-Napoli, Ricardo-Ricciardi, 1955. Primera edición en español: La disputa del Nuevo Mundo. Historia de una polémica. 1750-1900. México, FCE, 1960. Segunda edición, corregida y aumentada: México, FCE, 1982. Cf. también el estudio de Mario Casalla América en el pensamiento de Hegel. Admiración y rechazo. Buenos Aires, Catálogos, 1982.

44 Hegel, G.W.F.: Lecciones sobre filosofía de la historia universal. Citado por Ortega y Gasset en Obras completas, tomo II, p. 676.

45 Obras completas, o.c., tomo II, p. 676. 
o cuando se confunde la razón con el éxito y el plano descriptivo con el plano normativo. Entonces no sólo se está levantando acta de lo ocurrido, sino que además se está diciendo que ocurrió como debió porque hay una necesidad lógica, racional e inexorable, que ordena el devenir y a la que tenemos que ajustarnos para ser libres.

La visión de América de Hegel es buena muestra del despotismo entre ilustrado y totalitario de su pensamiento. América no tiene pasado ni presente, carece de historia y "Lo que hasta ahora acontece allí no es más que el eco del Viejo Mundo y el reflejo de ajena vida" 46 . Es naturaleza fracasada en su intento por devenir espíritu y por eso está condenada a la prehistoria o, dado el caso, a un ficticio e inocuo porvenir. Por lo pronto, el mejor de sus destino posibles es la extinción bajo el influjo civilizador de Europa y la asimilación a los procesos dialécticos que allí acontecen. Hegel propiciaba así argumentos al colonialismo contemporáneo mientras que su visión peyorativa de América pervivirá y sobrevivirá largamente bajo múltiples transformaciones y herencias.

En todo caso, cabe mencionar alguna reflexión de Ortega en la que, aun de manera puntual y fragmentada, se muestra más crítico a propósito de estas cuestiones. Una de ellas la encontramos en sus notas de trabajo y apunta hacia un cierto desenmascaramiento de la oposición cultura-barbarie que subyace a la visión hegeliana de América:

como Hegel ha expulsado de la historia a los salvajes, no advierte que todo pueblo clásico emerge de un íntimo salvajismo y de una barbarie, los cuales aun superados perduran y hace posible la plenitud. Mientras no se llegue a ver en qué sentido y cómo el pasado se conserva en historia y que hoy además de tan hipercultos somos salvajes y bárbaros y sin ese residuo de ambos estados no podríamos vivir, no se entenderá bien la historia ${ }^{47}$.

Aun cuando la barbarie, tal y como Ortega la menciona en esta breve anotación, sea un residuo de algo arcaico más que un momento mismo de la cultura, tal y como plantearía una filosofía netamente crítica, ese residuo es inextinguible y cuestiona la imagen que Europa se ha construido de sí misma cuando se ha confrontado con otros pueblos. En este sentido discurrían, y de manera más explayada, algunos planteamientos de Las Atlántidas (1924) y de otros escritos breves de ese año. Ortega señalaba entonces la relevancia actual de la etnología por su relativización, precisamente, de conceptos como el de barbarie y por su visión pluralista de la cultura, en detrimento de su horma eurocentrista y su sentido normativo. Por eso - apunta Ortega - si la cultura europea fuera portadora de alguna superioridad, ésta habría de consistir únicamente en reconocer su "esencial paridad" 48 con la china o la malaya, o en "creer que no lo es" y en volverse "problemática"49. La realidad histórica que conforman unas y otras culturas es por tanto plural. Ortega también procura desenmascarar el particularismo de la supuesta historia universal que los europeos han construido falazmente

46 Hegel, G.W.F.: Lecciones sobre filosofía de la historia universal. Citado por Ortega y Gasset en Obras completas, o.c., tomo II, p. 679.

47 Hegel. Notas de trabajo, o.c., pp. 86s. "La civilización es hija de la barbarie y nieta del salvajismo", había dicho Ortega en "Notas del vago estío" (1925). Citado Por Domingo Hernández en ibid., p. 87, nota 179.

48 Obras completas, o.c., tomo III, 2005, p. 757.

49 "El sentido histórico", en El Sol, 10 de julio de 1924, en Obras completas, o.c., tomo III, p. 698. 
bajo el punto de vista exclusivo y excluyente de su propia cultura, previamente erigida en "un ideal sobrehistórico" 50 . Durante tres siglos - prosigue - la ciencia histórica europea "ha pretendido deliberadamente tomar un punto de vista universal, pero, en rigor, no ha fabricado sino historia europea", tratando "los destinos no-europeos que habían llegado a su noticia (...) como formas marginales de lo humano, como accidentes de valor secundario, sin otro sentido que subrayar más el carácter substantivo, central, de la evolución europea" 51 . Evolución que, por medio de la teoría del progreso - plasmada de manera ejemplar en las lecciones de Hegel, precisamente, y perpetuada en Marx y otros hijos pródigos como Comte o Darwin - convertía además a "la cultura europea actual" en "el recipiente en que queda recogido" todo aquello "verdaderamente culto" 52 que haya habido en las culturas oriental, griega o romana, negando "positiva existencia histórica" 53 a todo pueblo que no pareciera contribuir a ese progreso. Frente a todo ello, Ortega abogaba por la distancia, la discontinuidad y la pluralidad históricas; o lo que es en definitiva lo mismo, por la razón histórica o por una hermenéutica capaz de "entender el sentido de lo que para nosotros no tiene sentido" 54 por su disparidad cultural. Quedaba así abierta la expectativa de "una historia universal policéntrica" cuyo "horizonte total se obtendrá por mera yuxtaposición de horizontes parciales, con radios heterogéneos que hacinados formarán un panorama de los destinos humanos bastante parecido a un cuadro cubista" ${ }_{55}$.

Por otra parte, los apuntes críticos de Ortega a propósito de la visión hegeliana de América tendrán, pese a su tibieza, una larga aunque indirecta y seguramente inesperada proyección. A través de su gran discípulo en el exilio, José Gaos, serán asimilados, reconducidos y desarrollados bajo nuevos y más críticos enfoques por algunos de los discípulos mexicanos de este último, en concreto por los integrantes del grupo "Hiperión" y especialmente por Leopoldo Zea. Este último publicaba su conocido estudio sobre el positivismo en México en $1943^{56}$ como resultado de la tesis doctoral que había desarrollado bajo la dirección de Gaos. Como apunta Tzvi Medin, para entonces Zea aún seguía siendo “orteguiano”, en el sentido de que en su estudio cabe reconocer la impronta del circunstancialismo y del perspectivismo $^{57}$ - además, podríamos añadir, de la teoría de las ideologías de Manheim- . Una impronta que, en realidad, no abandonará nunca, si bien bajo sesgos diferentes y hasta opuestos a los de Ortega. En su caso, salvar la circunstancia - ya sea mexicana o latinoamericana - no se traducirá en la necesidad de incorporarla en el concierto de la gran cultura y ciencia europeas sino, más bien al contrario, en el cuestionamiento de esta última por su proyección enajenante y anegadora hacia el exterior. De ahí, precisamente, su radicalización del giro mexicano e hispanoamericano que Gaos había imprimido al historicismo de Ortega,

50 Las Atlántidas, en Obras completas, o.c., tomo III, p. 772.

51 Ibid., p. 765.

52 "El sentido histórico", en Obras completas, o.c., tomo III, p. 696.

53 Las Atlántidas, en Obras completas, o.c., tomo III, p. 765.

54 Ibid., p. 770.

55 Ibid., p. 766. Este fragmento es citado por Domingo Hernández en Hegel. Notas de trabajo, o.c., p. 43, nota 365.

56 El positivismo en México: nacimiento, apogeo y decadencia. México, FCE, 1943-44 (2 vol.).

57 Cf. Medin, Tzvi: Entre la jerarquía y la liberación. Ortega y Gasset y Leopoldo Zea. México, UNAM-FCE, 1998, pp. 49s. 
sobre todo durante los primeros años de su exilio ${ }^{58}$. A partir de los años cincuenta - comenta Medin - reconducirá el sentido de la razón circunstancial hacia la semántica de la liberación, en detrimento de la semántica de la jerarquía. Asumir y encarar la circunstancia mexicana o latinoamericana significará entonces adquirir conciencia crítica de su marginalidad y de los diversos y sucesivos encubrimientos que ha soportado desde la conquista hasta el presente, bajo figuras como la utopía cristiana y el progreso o conceptos como el liberalismo. Zea observará en este sentido cómo la interpretación lineal y ascendente de la historia propia de la inteligencia europea coincide con el ascenso social y político del sujeto burgués y con su expansión colonialista, erigiéndose a sí mismo en sujeto universal y prototipo de humanidad. Es éste el contexto en el que abundarán las referencias a Hegel, a su divinización de dicho sujeto y a su visión de América, obviamente críticas, si bien Zea se apropia al mismo tiempo de su método dialéctico para confrontar la conciencia latinoamericana con sus propias "yuxtaposiciones" europeas, y liberar así su negatividad latente. Su visión del historicismo se encaminará por tanto hacia el rescate y la reivindicación de la realidad histórica encubierta bajo las grandes construcciones europeas de la universalidad. Ortega había sospechado de estas últimas y se había desmarcado de sus expresiones hegelianas, pero sólo hasta cierto punto a juicio de Zea, en la medida en que su historicismo no podía desligarse de su contraposición entre pueblos-masa y pueblos creadores. Por eso la representación cubista de la historia se antojaría insuficiente para Zea, quien encontró más bien en el muralismo mexicano un claro ejemplo de expresión cultural propia, consciente de su circunstancia y rebelde frente a su marginalidad y dependencia ${ }^{59}$.

4. "Hegel y la filosofía de la historia" y su posterior versión, "En el centenario de Hegel", finalmente, mantienen el tono más bien expositivo de los ensayos anteriores, centrándose también en la filosofía de la historia del pensador alemán. No obstante, ésta ya no es enfocada a propósito de cuestiones más o menos particulares como el problema de la historiología o la significación de América en el contexto de la racionalidad moderna, sino que lo hace a partir de su inquietud fundamental, a saber: el caos y la contradicción que, al menos aparentemente, envuelven al acontecer histórico, cuestionando su sentido y su racionalidad. O dicho de otra manera, el problema de identificar un substrato común a los hechos inconexos y en tropel que constantemente se suceden en el escenario de la historia, desafiando a toda inteligencia que pretenda reducirlos sin traicionar la vitalidad de los mismos. En

58 Cf. El pensamiento hispanoamericano. El Colegio de México, 1944; Pensamiento de lengua española. Stylo, 1947; sus antologías Pensamiento español. SEP, 1945 y Antología del pensamiento de lengua española en la edad contemporánea. Séneca, 1945; En torno a la filosofía mexicana. Porrúa y Obregón, 1952-53) y Filosofía mexicana de nuestros días (UNAM, 1954). Gaos concebirá la razón circunstancial como un rasgo genealógico del pensamiento de lengua española, palpable por ejemplo en la reflexión de los jesuitas criollos novohispanos del siglo XVIII y previo, por tanto, a su elaboración orteguiana. Asimismo, si para Gaos el pensador de lengua española - entendiendo también por tal al americano - es, como en Ortega, un "espectador" de la cultura de raíz europea, está llamado a apropiarse de ella no sólo para responder a las necesidades profundas de su circunstancia, sino también para regresar a esa cultura cargado de interpelaciones. Con Gaos, el "lógos del Manzanares" adquirirá una proyección americana que no había llegado a desahogarse en la experiencia argentina de Ortega y que se tradujo, además, en una amplia exploración de autores, periodos y acotaciones hermenéuticas de la filosofía en lengua española.

59 Cf. Medin, Tzvi: o.c., especialmente el cap. IV (pp. 77-137). 
definitiva, el problema de responder a la pregunta, no ya por lo que pasa en la historia, sino, más aún, por quién la soporta y la hace, por quién es su sujeto, máxime cuando se aspira a una reconstrucción universal de la misma. “¿Quién es el 'alguien’, el 'mismo' de la Historia que salta y late bajo sus sucesos?" ${ }^{60}$.

Ortega identifica así dos problemas fundamentales, que en realidad son las dos caras de uno solo: por una parte, la justificación de la historia y la consecuente elucidación de una racionalidad subyacente a los hechos aparentemente inconexos que la conforman; por otra, la definición de una identidad o un sujeto universal, capaz por tanto de trascender las limitaciones fácticas del yo individual y de dar cuenta de la convivencia humana en toda su plenitud, más allá de difusas acotaciones sociales. La contradicción entre unos hechos históricos y otros, y aquella otra entre unos sujetos y otros es, en realidad, la misma contradicción sujeto-objeto que recorre todo el pensamiento de Hegel, y para resolverla es preciso hallar una perspectiva omnicomprensiva: "es preciso mirar el Universo, no desde dentro de él, sino coincidiendo con él, cuando tal universo sea nuestro punto de vista - no el nuestro sino precisamente el suyo, lo universal, lo absoluto-" ${ }^{61}$. Desplegar esa mirada no es otra cosa, para Hegel, la tarea misma de la filosofía, que, en lo que a la realidad histórica se refiere, apunta hacia una plenitud inalcanzable para otras interpretaciones que no han logrado despegarse de un punto de vista parcial, consistente "en elegir una clase de hechos como realidad fundamental de que todos los demás son consecuencia” ${ }^{2}$. Tal sería el caso - apunta Ortega - de la interpretación empirista, la cual se limita a ordenar los hechos positivos en base a la observación de sus regularidades, o la económica, que pivota sobre los hechos de este orden, u otras menos comunes como la bélica e incluso la hidrológica. Los ejemplos serían innumerables y el problema radica en hallar un punto de vista que contenga todos los demás. Hegel - prosigue Ortega, identificando uno de los grandes argumentos del idealismo - lo encuentra en el pensamiento, pues "es la única realidad que está siempre delante de sí misma, que consiste, precisamente, en verse a sí misma." Es pura "reflexividad", entendida como un proceso a lo largo del cual el sujeto lucha por apropiarse de lo otro de sí y se hace autoconsciente a medida que se torna legible todo aquello que piensa. Es un "darse cuenta de sí mismo" 63 cuya mismidad se extiende mucho más allá de la condición individual o colectiva de un sujeto particular, identificándose con el sistema de ideas, normas y valores objetivos que lo determina y envuelve, hasta alcanzar su plenitud sólo en la condición universal. Tal es el proceso dialéctico del Espíritu, "realidad que se da luz a sí mismo" y por tanto única realidad como tal, que, al ser idéntica a sí mismo y depender solamente de sí misma, es la sustancia de la libertad.

He aquí lo que verdaderamente pasa en la Historia. He aquí el 'alguien', el 'mismo' - a quien la Historia universal le pasa: Es el Espíritu, el Pensamiento. La Historia es la biografía del espíritu universal. Durante toda ella lucha consigo misma para conquistarse, para descubrirse, para reconocerse $-\mathrm{y}$ como el Espíritu no es sino ese conocerse- para llegar a ser con plenitud 'sí mismo'. Pero conocerse el espíritu a

60 "En el centenario de Hegel", Obras completas, o.c., tomo V, p. 690.

61 "Hegel y la filosofía de la historia", Ibid., tomo VIII, p. 526.

62 "En el centenario de Hegel", ibid., tomo V, p. 692.

63 "Hegel y la filosofía de la historia", ibid., tomo VIII, p. 527. 
sí mismo como única realidad es una misma cosa, saberse libre. Para Hegel sólo es propiamente libre lo que sea único. Por eso es la Historia, según él, el progreso en la idea de libertad: porque la Historia es el proceso en que el espíritu descubre que él es la única realidad que existe. Descubre, pues, al cabo de la Historia, su soledad, su unicidad, su libertad ${ }^{64}$.

La libertad no se juega por tanto en el arbitrio de los actos individuales, sino en la identificación de éstos con el sistema de instancias objetivas que los determina y que en cada momento de la historia escenifica y materializa la progresión autorreflexiva universal del Espíritu. No se juega por tanto en la pluralidad negativa o en la negación de lo otro de sí, sino en la identidad o en la reconciliación con lo otro de sí. Como ya adelantara Ortega en "Hegel y América", la expresión hegeliana de esta identidad reconciliada es el estado, el cual evoluciona desde la libertad exclusiva del déspota asiático hasta el reconocimiento de la libertad en todo hombre alcanzado en el mundo germánico.

Al igual que en sus anteriores ensayos sobre Hegel, en medio del tono general expositivo y casi descriptivo se entreabren algunas perspectivas críticas, los cuales se enriquecen, nuevamente, con la lectura de algunas de sus notas de trabajo. Ortega hace explícita su obvia distancia de la filosofía hegeliana de la historia, a la que define como "método autoritario"65 (192/419) por una razón fundamental nada difícil de adivinar: Hegel interpreta la historia antes de siquiera conocerla o de sumergirse en sus hechos singulares, adaptándola a la lógica abstracta del Espíritu que previamente ha construido especulativamente, y de la que no es más, en definitiva, que un desarrollo parcial. De ahí la necesidad de reducir el Espíritu a la vida, término este último, por cierto, que el propio Hegel - recuerda Ortega - había empleado en sus escritos de juventud. "Si yo hubiera tenido derecho a suponer en el auditorio algún conocimiento previo sobre Hegel" - afirma a propósito del desdén de este último hacia el papel histórico del individuo - en lugar de espíritu "habríamos hablado entonces de 'vida', que fue el vocablo con que el mismo Hegel, joven aún, bautizó primero lo que luego, y a mi juicio con error, iba a denominar "espíritu" " ${ }_{66}$. Hablar de vida en lugar de espíritu implicaría entonces entender la realidad histórica a partir de la acción de los individuos y de la incertidumbre que siempre la envuelve. Al igual que el Espíritu, bien es cierto, la vida es conocimiento de sí misma, lucha por comprender su propia incomprensión y problema para sí misma. “№ es esto lo característico de la vida humana? ¿No es nuestro vivir sentirse cada cual sumergido en un absoluto problema?" ${ }^{67}$ Ciertamente, entre el Espíritu y la vida cabe una cierta analogía, pero la distancia entre ambos conceptos se torna abismal cuando entendemos nuestro vivir en un sentido orteguiano, a saber, como radical inseguridad y naufragio, enigma y constante interpretación de sí misma, sin ningún asidero posible a un relato preestablecido que resuelva sus dilemas e ilumine sus oscuridades o la haga transparente a sí misma. Sin ese relato, la vida es sólo parcial realización de sí misma, "afán de transparencia, parcial iluminación, constante descubrimiento y averiguación, mas por lo mismo nunca plenaria

64 Ibid., p. 530.

65 "En el centenario de Hegel", ibid., tomo V, p. 695.

66 "Hegel y la filosofía de la historia", ibid., tomo VIII, p. 533.

67 "En el centenario de Hegel", ibid., tomo VIII, p .695. 
claridad"68. Aun es más, "la vida es lo contrario del Espíritu - que es inmanente y consiste en saberse", pues "no se sabe nunca a sí misma, se supone de supuestos que no sabe y lo que sabe lo sabe desde esos supuestos. Por esto es vida ejecución, novedad siempre inesperada."69, "un buscarse a sí misma" o "una lucha por su propia autenticidad"70.

68 Ibid., p. 697.

69 Hegel. Notas de trabajo, o.c., p. 110.

70 Ibid., p. 48.

Daimon. Revista Internacional de Filosofía, nº 67, 2016 